\title{
Altered Inhibition of Dentate Granule Cells during Spatial Learning in an Exploration Task
}

\author{
Edvard I. Moser \\ Department of Neurophysiology and Institute of Psychology, University of Oslo, 0317 Oslo, Norway, and Centre for \\ Neuroscience, University of Edinburgh, Edinburgh EH8 9LE, United Kingdom
}

To investigate the extent to which inhibitory interneurons control impulse flow through the dentate gyrus during spatial learning in an exploration task, dentate field potentials were recorded in response to paired stimulation of the perforant path while rats rested or explored. Recurrent inhibition of the granule cells was measured as the reduction of the second waveform when a population spike was present in the first. Both the population spike and the field EPSP (fEPSP) were suppressed at interstimulus intervals shorter than $\sim 40$ msec.

Consistent differences were observed between potentials recorded at equivalent brain temperature in the exploration and resting (reference) conditions. During exploration, the fEPSP of the second (test) waveform was reduced further compared with reference potentials with a similar response to the first (conditioning) stimulus. This reduction was observed only when the first pulse elicited a population spike. The population spike of the second waveform was facilitated compared with reference potentials with similar fEPSP slopes. These observations suggest that exploration is coupled to increased inhibition on the perforant-path terminals or the dendrites of the granule cells, whereas the inhibition on the somata is decreased. The two phenomena were not correlated and followed different time courses. The suppression of the fEPSP decayed gradually, although it was still present at $15 \mathrm{~min}$, whereas the facilitation of the population spike was stable. Together, these changes, which likely involve different populations of interneurons, may focus and amplify incoming signals from the entorhinal cortex.

Key words: hippocampus; exploration; spatial learning; memory; inhibition; paired pulses
Convergent evidence from electrophysiological and lesion studies suggests that the hippocampus participates in spatial learning or formation of cognitive maps (O'Keefe and Dostrovsky, 1971; O'Keefe and Nadel, 1978; Olton et al., 1978; Morris et al., 1982, 1990; Jarrard, 1993). Much of the processing necessary for establishing memory traces is likely to take place in the dentate gyrus. Although the entorhinal cortex has powerful direct connections with each of the hippocampal subfields (Steward, 1976; Witter et al., 1988; Yeckel and Berger, 1990), spatial learning requires that the dentate gyrus be intact (Sutherland et al., 1983; Walsh et al., 1986; McNaughton et al., 1989; Armstrong et al., 1993; Conrad and Roy, 1993).

Excitatory synapses in the dentate gyrus have significant capacity for change (Bliss and Lømo, 1973). During spatial learning in an exploration task, transmission across the perforant-path synapses of the dentate granule cells is enhanced temporarily (Moser et al., 1994). However, the output from the granule cells is controlled by an extensive network of heterogeneous interneurons in the hilus and the dentate gyrus (Amaral, 1978; Han et al., 1993), mediating both recurrent (Andersen et al., 1966) and feedforward (Buzsáki, 1984) inhibition. The axons of these interneurons diverge extensively, contacting hundreds or thousands of granule cells across a significant part of the septotemporal axis of the

Received July 5, 1995; revised Sept. 19, 1995; accepted Nov. 1, 1995.

This research was supported by grants from the Institute of Psychology, University of Oslo, and the Human Frontiers Science Program. This work was done in P. Andersen's laboratory. I thank P. Andersen, E. Hartveit, T. Lømo, R. G. M. Morris, M. B. Moser, and O. Paulsen for valuable discussion, and Tore Eriksen, Eva Aaboen Hansen, Bruce Piercey, and Trond Reppen for technical assistance.

Correspondence should be addressed to Edvard Moser, Department of Neurophysiology, P.O. Box 1104, Blindern, 0317 Oslo, Norway.

Copyright (C) 1996 Society for Neuroscience $0270-6474 / 96 / 161247-13 \$ 05.00 / 0$ dentate gyrus (Andersen et al., 1966; Struble et al., 1978; Scharfman, 1991; Halasy and Somogyi, 1993; Han et al., 1993; Buckmaster and Schwartzkroin, 1995). Many of the interneurons have axons terminating on the somatic region of the granule cells; others make synapses primarily with the more distal parts of the granule-cell dendrites.

It is possible that the inhibitory control of the impulse flow through the dentate gyrus is altered when unfamiliar information enters the hippocampal formation. Relaxed inhibition would enable maximal postsynaptic depolarization, and possibly NMDA receptor-mediated synaptic modifications, in relevant target cells. Alternatively, increases in inhibition of the principal cells might ensure that input is provided to a quiescent network, which may be necessary to avoid interference between preceding activity and the incoming signals (McNaughton and Morris, 1987).

In the present study, inhibition of the granule cells was measured by recording dentate field potentials in response to paired stimulation of the perforant path while rats explored an unfamiliar environment. The relative size of the second of two consecutive waveforms reflects two opposing factors: (1) facilitation caused by residual calcium in the nerve terminals when the second impulse arrives (Katz and Miledi, 1968; Lømo, 1971; Creager et al., 1980; Wu and Saggau, 1994); and (2) inhibition caused by activation of inhibitory interneurons that feed back on the granule cells (Andersen et al., 1966; Lømo, 1971). The latter component is expressed only if granule cells are discharged by the first stimulus. The two factors can be dissociated by analyzing the relationships between the field EPSPs (fEPSPs) and population spikes of the two responses separately below and above the spike threshold of the first response. 


\section{MATERIALS AND METHODS}

Surgery. Twenty-five male Long-Evans rats (250-500 gm) were anesthetized with urethane $(1.5 \mathrm{gm} / \mathrm{kg}$, i.p.; acute experiments) or Equithesin (165 mg of chloral hydrate, $84 \mathrm{mg}$ of magnesium sulfate, and $40 \mathrm{mg}$ of pentobarbital $/ \mathrm{kg}$ body weight; chronic experiments). The animals were mounted in a sterentaxic frame. A bipolar stimulation electrode (SNEX 100, Rhodes Medical Instruments, Woodland Hills, CA) was positioned in the right angular bundle (anteroposterior, $7.5-8.0 \mathrm{~mm}$; mediolateral, $4.3 \mathrm{~mm}$, relative to bregma), and an insulated tungsten recording elec trode was lowered into the ipsilateral dentate hilus or granule cell layer (anteroposterior, $4.0 \mathrm{~mm}$; mediolateral, $2.6 \mathrm{~mm}$, relative to bregma) until a positive-going fEPSP was elicited by stimulation in the angular bundle. Two stainless steel screws serving as indifferent and ground electrodes were fixed to the frontal bones. A precalibrated thermistor $0.5 \mathrm{~mm}$ diameter, resolution $<0.07^{\circ} \mathrm{C} ; 111-802$ EAJ-B01, Fenwal Electronics, Milford, MA) was placed in the cortex of the contralateral hemisphere just above the dorsal hippocampus. In the chronic experiments, the leads from electrodes and thermistors were connected to a socket, the array was encased in dental acrylic, and the rats were given $>1$ week for recovery before any electrophysiological testing began.

Electrophysiology. Dentate field potentials were recorded in response to paired stimulation of the perforant path at $0.2 \mathrm{~Hz}$ (rectangular pulses, $50-1000 \mu \mathrm{A}, 100 \mu \mathrm{sec}$ ). The interval betwecn the conditioning and test volleys was varied between 5 and $250 \mathrm{msec}$, but most behavioral experiments were conducted at $20 \mathrm{msec}$. The pulse intensity was varied across a broad range, usually with the two volleys at similar intensity. In a subset of 14 experiments (acute and chronic), the intensity of the test pulse was fixed, either below or above the threshold for a population spike in the first waveform, whereas the conditioning pulse was varied systematically.

The chronically implanted rats were connected to the recording equipment via a small preamplifier and a counterbalanced cable. All potentials were amplified 200-1000 times, filtered at $1 \mathrm{~Hz}$ (high pass) and $10 \mathrm{kHz}$ (low pass), and sampled at $35 \mathrm{kHz}$ by a computer. Brain temperature was recorded simultaneously with each fEPSP in all experiments.

fEPSP slopes were measured using linear regression between two fixed time points on the early rising phase of the fEPSP (when the amplitude is less than one-third of the maximum before the population spike). The population spike amplitude was taken as the vertical distance between the peak and a joint tangent to the preceding and succeeding positivities. At interstimulus intervals of 5-10 msec, the rising part of the second potential overlapped with the falling phase of the first response. In these cases, averaged unconditioned waveforms were subtracted from the mixed potentials to enable the fEPSP and the population spike of the second potential to be measured in isolation. Inhibition of the fEPSP was expressed either as the ratio between the fF.PSP slopes of the second and the first potential (paired-pulse ratio) or as the ratio between the fEPSP of the second and the population spike of the first waveform. Inhibition of the population spike was estimated by contrasting the population spike-fEPSP slope ratio of the first and the second potentials.

Behavioral tasks. Field potentials and brain temperature were recorded in two situations in all animals as follows: (1) while the rat was exploring novel objects in an open field, and (2) while the same rat was resting at decaying brain temperature in its home cage (reference situation). With this procedure, potentials taken during exploration could be compared with potentials recorded at the same brain temperature $\left( \pm 0.07^{\circ} \mathrm{C}\right)$ during rest (reference session), thereby avoiding any temperature-related effects (Moser et al., 1993a).

Exploration. In the exploration task (Moser et al., 1994), the rats explored novel objects in an open field for $15 \mathrm{~min}$. The rat was placed with its home cage into a hole in the center of a plywood open-field apparatus $\left(96 \times 96 \times 56 \mathrm{~cm}^{3}\right)$. The rim of the home cage was $2-3 \mathrm{~cm}$ above the floor level, allowing the rat to enter the outcr part. Six novel landmarks (diameter, $\sim 20 \mathrm{~cm}$; height, $\sim 15 \mathrm{~cm}$ ) were placed in the field. The position of the rat was tracked at $10 \mathrm{~Hz}$, and the area (number of 3 $\times 3 \mathrm{~cm}^{2}$ squares) visited was calculated for each 1 min block of each trial. Throughout one set of exploration sessions, potentials were sampled in response to a series of pulses at five intensities repeated continuously in ascending order. Only one intensity was used in experiments addressing the time course of the field potential changes. In the latter tests, exploration was preceded by $5 \mathrm{~min}$ of baseline recording with the rat resting in its shielded home cage (see below).

Reference task. Two reference sessions were conducted daily, one before and one after the exploration. Reference potentials were sampled at a wide range of brain temperatures while the rat was resting in its home cage inside a black, sound-attenuated box twice as high as, but not deeper or wider than, the home cage. Brief handling of the rats was sufficient to attain a high brain temperature at the start of these sessions. The brain temperature decayed slowly in this condition, usually covering the entire range of temperatures measured during exploration within $1 \mathrm{hr}$. Inputoutput relationships of dentate field potentials were determined once or twice at the end of each reference session. At this stage, the brain temperature declined very slowly, and potentials sampled across a wide range of closely spaced pulse intensities still were within a narrow window of temperatures. The pulse intensity ascended from well below to well above the spike threshold.

The behavior was monitored continuously during the reference recordings. Signals occurring during locomotion and during rapid eye movement sleep periods were not used as reference records. Slow-wave sleep episodes were retained, because fEPSPs during slow-wave sleep (curled posture and closed eyes) do not appear to differ from potentials sampled at comparable brain temperatures during immobile resting in awake rats (Cain et al., 1994). Data collected according to similar criteria (E. Moser, unpublished data) confirm this impression (sleep-awake ratio: fEPSP slope, $0.97 \pm 0.05$; population spike amplitude, $1.02 \pm 0.06 ; n=7$ ).

Comparison of potentials. The reference potentials (sampled at various levels of intensity) were sorted according to the fEPSP slope or the population spike amplitude of the first or the second potential. This gave fairly continuous distributions covering the entire range of values recorded during exploration. The close spacing allowed test fEPSPs recorded during exploration to be compared with test fEPSPs of reference pairs with similar fEPSP slopes or spike amplitudes in the first response ( $\pm 10 \%$; average difference, $<0.5 \%$ ). Moreover, population spikes of test potentials sampled during exploration could be compared with pairs of reference potentials in which the second waveform had a similar fEPSP slope ( $\pm 10 \%$; average difference, $<0.1 \%$ ).

Because only potentials recorded at similar brain temperature were compared, the matching procedure (see above) was restricted to potentials taken during the first 3-4 min of exploration, when the brain temperature was within the window at which the input-output functions were determined during the reference session $\left( \pm 0.15^{\circ} \mathrm{C}\right)$. Estimates of the additional time course of changes in paired-pulse ratios during exploration had to rely on temperature matching alone. In analyses of the time course of the changes in inhibition, pairs of reference potentials from the two resting sessions were sorted according to temperature and mean values were calculated for each $0.07^{\circ} \mathrm{C}$ step. Potentials sampled during each 1 min block of the exploration session then were compared with potentials taken at the same (or the closest) brain temperature during the reference sessions.

Statistical analyses. fEPSP slopes and spike amplitudes from the exploration session were expressed as ratios of the matched reference values. In the tine-course experiments, sessions with a population spike in the conditioning response $(n=34)$ were analyzed separately from those with stimulation below the spike threshold $(n=12)$. Quantification of changes in spike amplitudes was limited to cases with clear population spikes $(>0.5 \mathrm{mV})$. Experiments with thermistor failure $(n=6)$ or baseline fEPSP values exceeding $10 \%$ of the temperature-matched reference values $(n=1)$ were discarded from the analysis. Five experiments were excluded because the rat failed to rest during the determination of input-output relationships in the reference condition. The results were evaluated with repeated-measures ANOVA, two-tailed Student's $t$ tests, or Pearson's product-moment correlations.

\section{RESULTS}

\section{Suppression of the test response in anesthetized and resting animals}

\section{Background}

Synaptic transmission and discharge probability in dentate granule cells are modified by a conditioning pulse to the perforant path (Lømo, 1971). Volleys preceding the test stimulus by $<200-$ $300 \mathrm{msec}$ potentiate the fEPSP. This facilitation is relatively independent of the pulse intensity. The effect is opposed by a concomitant reduction of the test potential lasting $100-150 \mathrm{msec}$ (Andersen et al., 1965; Lømo, 1971). The latter effect is expressed only if the granule cells discharge in response to the first pulse, which suggests that the recurrent inhibitory circuit is activated (Andersen et al., 1966). In exposed hippocampi of rabbits, only the population spike, but not the fEPSP, of the test potential was 
A

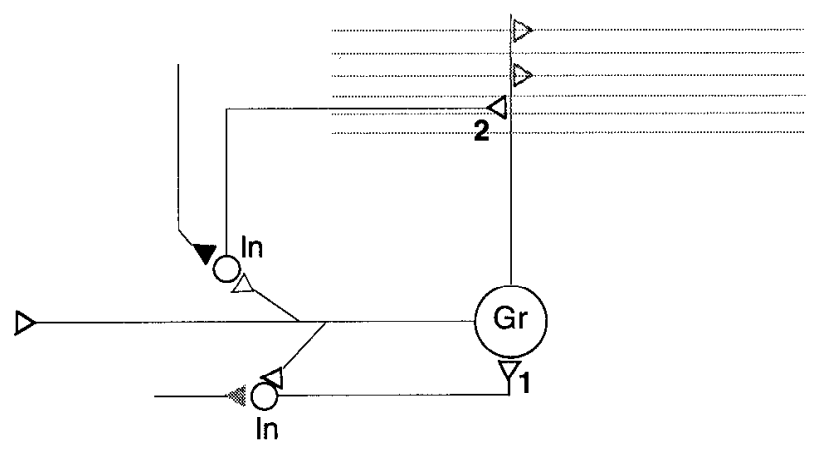

B

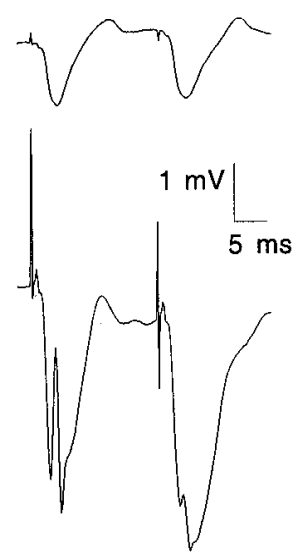

D

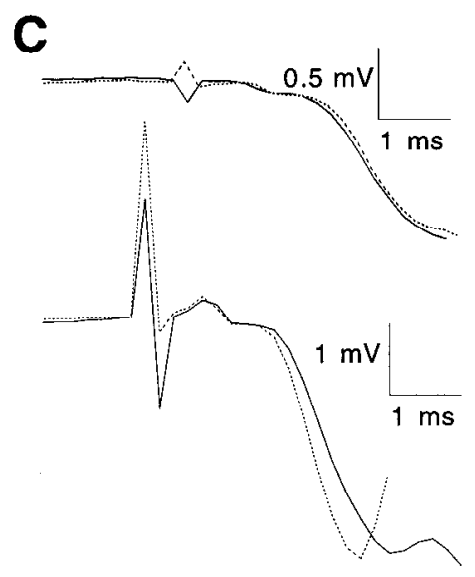

E

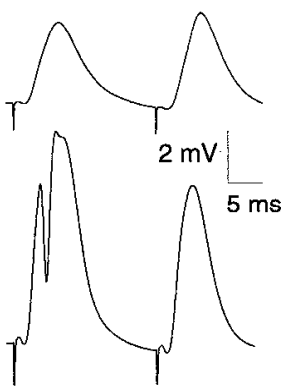

local interneurons (Bakst et al., 1986; Halasy and Somogyi, 1993; Han et al., 1993; Buckmaster and Schwartzkroin, 1995) that are contacted by mossy fibers (Leranth et al., 1990; Baude et al., 1993) ( 2 in Fig. 1A). The suppression of dentate EPSPs and population spikes by a conditioning pulse to the perforant path, therefore, was reinvestigated in intact rat brains.

\section{Effect of stimulation strength}

When the first stimulus evoked a population spike, field potentials in the dentate gyrus were suppressed in response to a perforantpath stimulus given $20 \mathrm{msec}$ later (Figs. $1 B-E, 2 A-C$ ). Both the fEPSP and the population spike then decreased regardless of whether the test intensity was constant (Fig. $2 A$ ) or matched the intensity of the first pulse (Fig. $2 B, C$ ). The suppression increased with increasing conditioning population spikes. Conditioning pulses stronger than those eliciting maximal population spikes failed to suppress the test responses further (Fig. 2A). fEPSP reduction did not require a population spike in the test response. The decrease in the fEPSP never was sufficient to explain the spike reduction of the second wave (Fig. $2 B, C$ ). Below the spike threshold, the fEPSP was not suppressed, and a slight facilitation could be observed (Fig. $2 A, B$ ). The same pattern of effects was recorded in the molecular layer (5/5 experiments; Fig. $1 B, C)$ as in the granule cell layer (64/67 experiments; Fig. 1D,E). Recordings from anesthetized rats and freely moving rats during rest showed similar results.

\section{Effect of pulse interval}

Both the test fEPSP and the test population spike were inhibited at intervals from 5 to $40 \mathrm{msec}$ or more, with the greatest inhibition occurring at $5 \mathrm{msec}$ (fEPSP slopes, $<50 \% ; n=12$; Fig. $2 D$ ). At $20 \mathrm{msec}$, the test $\mathrm{fEPSP}$ was $10.6 \pm 3.1 \%$ smaller than the fEPSP of the conditioning response (pulse 1 and 2 had similar strength). The time courses of the fEPSP and spike reduction were remarkably parallel (suppression lasting 40 and $50 \mathrm{msec}$, respectively; median values). Both the magnitude and the duration of the inhibition likely were underestimated because of the simultaneous facilitation of the perforant-path signals (peaking at $15-20 \mathrm{msec}$ in experiments conducted below the spike threshold) (see also Lømo, 1971).

Thus, the suppression of the test fEPSP and population spike is correlated strongly with the presence of a population spike in the preceding conditioning response. Both types of reduction are limited to the time window during which most of the inhibition is likely to take place, because IPSPs recorded from granule cells last $<100-150 \mathrm{msec}$ (Andersen et al., 1966; Fournier and Crepel, 1984). 'I 'hese observations suggest that the suppression of the test response reflects recurrent inhibition, acting either on the perforant-path terminals or the granule-cell dendrites (fEPSP) or on the somatic region of the granule cells (population spike).

\section{Relationship between test response suppression and brain temperature}

An analysis of changes in paired potentials during exploration requires knowledge of their sensitivity to changes in brain temperature. Rising brain temperature during exploration increases the fEPSP slope, decreases the amplitude of the population spike, and decreases the latency of all components of single perforantpath granule-cell field potentials (Moser et al., 1993a). In the present study, the ratio between the fEPSP slopes of the conditioning and test response decreased when the brain was warmed in awake but resting rats (median correlation, $r_{(25)}=-0.68$ for reduced (Lømo, 1971). This implies that the axons of a majority of active hilar and dentate interneurons feed back on the somatic region of the granule cells ( 1 in Fig. $1 A$ ). However, recent work has demonstrated a dense innervation of the molecular layer by 
A

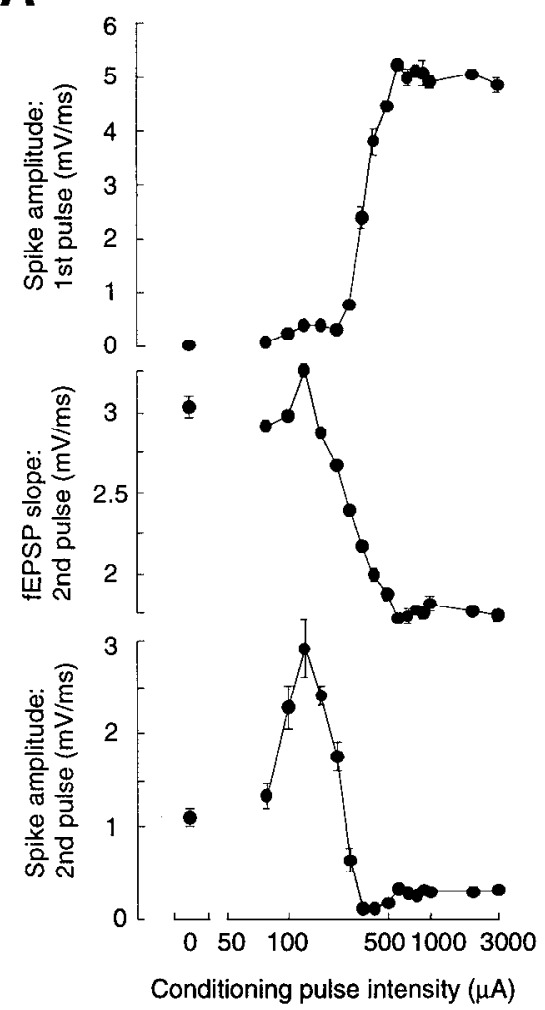

B
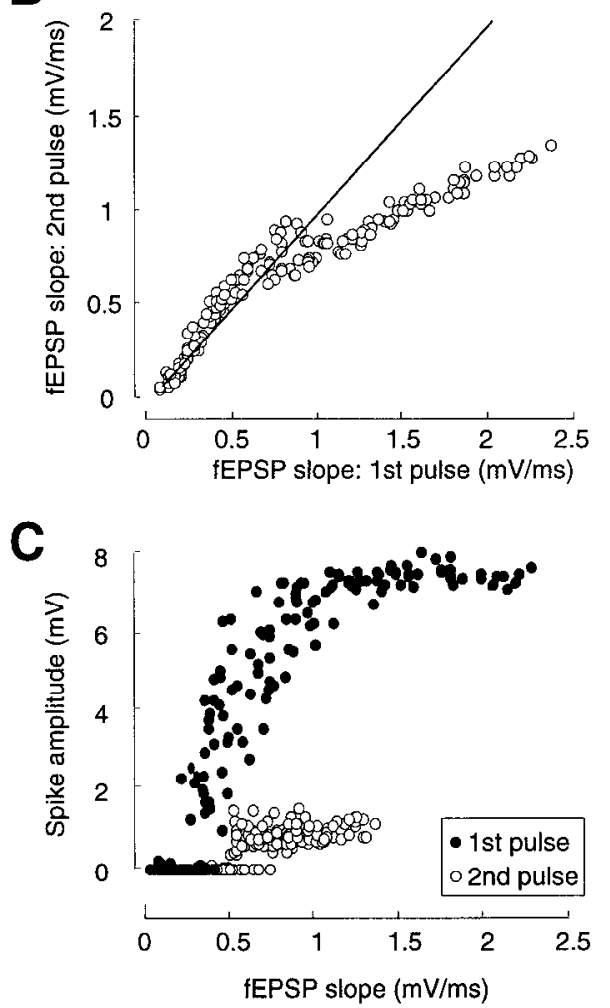

D
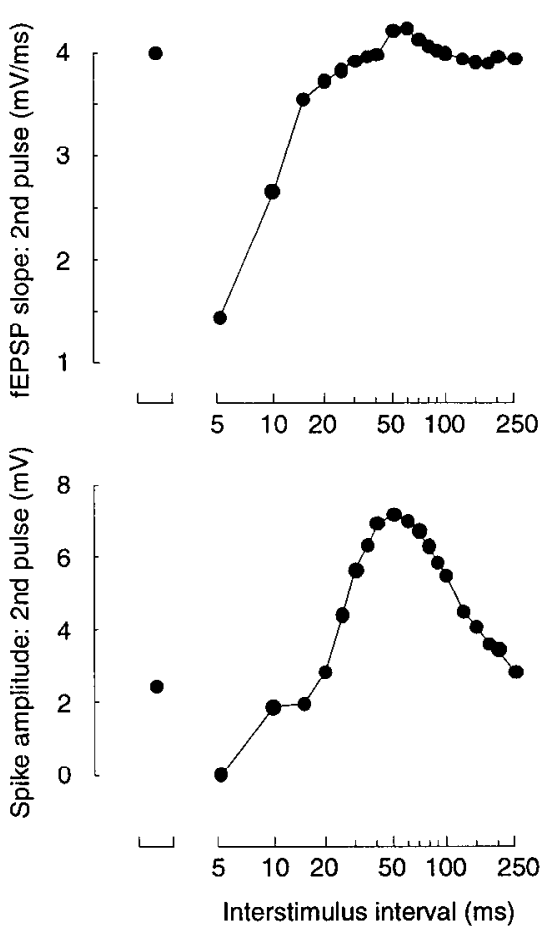

1st potential

2nd potential

Figure 2. Relationship between intensity of the first stimulus and suppression of $\mathrm{fEPSP}$ and population spike of the second response during urethane anesthesia. $A$, Spike amplitude of the first potential and fEPSP slope and spike amplitude of the second potential (mean \pm SEM), expressed as a function of the strength of the conditioning pulse. The intensity of the test pulse was kept constant. $B$, Relationship between the fEPSP slopes of the first and the second response in an experiment in which the two pulses had similar intensity. Similar slope values fall on the straight line. Each circle represents a single response. Note suppression of the second fEPSP above a threshold at $0.5-0.7 \mathrm{mV} / \mathrm{msec}$. The threshold for a population spike in the first waveform was $\sim 0.3 \mathrm{mV} / \mathrm{msec}$ (see C). $C$, Relationship between fEPSP slope and spike amplitude for each of the waveforms (same experiment as in $B$ ). The population spike of the second waveform clearly is reduced. $D$, Effect of interstimulus interval on the fEPSP slope and the spike amplitude of the second potential at an intensity that elicited a population spike in the first potential (mean \pm SEM). All error bars are too small to be seen on the figure.

cxpcriments with a population spike in the first response and $r_{(7)}$ $=-0.46$ for recordings below the spike threshold; the pairedpulse ratio decreased $4.3 \pm 0.8$ and $1.6 \pm 4.6 \% /{ }^{\circ} \mathrm{C}$, respectively). Because the relationship appeared to be independent of discharge in the granule cell population, the effect may reflect changes in the perforant-path synapses themselves. When the temperature rises, the synaptic release process is speeded up (Katz and Miledi, $1965)$, and it is possible that the nerve terminals contain less residual $\mathrm{Ca}^{2+}$ after arrival of the second pulse. This will result in decreased paired-pulse ratios at high temperatures.

Temperature also influenced the relationship between the fEPSP and the population spike of the conditioning and test responses. fEPSPs of a given magnitude elicited progressively smaller population spikes as the brain temperature increased [median correlation between temperature and spike amplitudefEPSP slope ratio, $r=-0.90$ (conditioning response) and $r=$ -0.48 (test response); $n=17$ ]. The reduction in spike amplitudefEPSP slope ratio was similar for the conditioning $(27.7 \pm 8.5 \%$ / $\left.{ }^{\circ} \mathrm{C}\right)$ and the test $\left(18.9 \pm 6.8 \% /{ }^{\circ} \mathrm{C}\right)$ responses, which suggests that intracellular factors such as membrane hyperpolarization and increased input resistance (Hodgkin and Katz, 1949; Thompson et al., 1985) are involved.

Because the brain temperature generally increases $1-2^{\circ} \mathrm{C}$ during an exploration session (Moser et al., 1993a), the above analyses suggest that changes in the relationship between paired responses during behavioral tasks be compared with control potentials sampled at closely similar brain temperatures.

\section{Strategy for detecting changes in paired responses during exploration}

Changes in inhibitory control of perforant-path granule cell transmission during a spatial learning episode were studied by letting rats explore new landmarks in an open field with their home cage as a base. fEPSPs were recorded in response to two consecutive stimuli, usually of equal intensity. To avoid interference from discharge-related aftereffects in the granule cells (Fournier and Crepel, 1984), the interstimulus interval was set to $20 \mathrm{msec}$ in most cases.

More interneurons likely are activated before the second than before the first of the two perforant-path stimuli. Thus, any change in inhibition on the granule cells is likely to affect the second response preferentially. Inhibition-related effects will be expressed in paired potentials only if granule cells are discharged by the first stimulus, however. To determine whether exploration is associated with such alterations in the second response, perforant-path granule-cell potentials were recorded in response to five stimulus pairs of increasing intensity (Fig. 3). One intensity was well below the threshold for eliciting a population spike. The sequence was repeated throughout the exploration session. Potentials at each intensity were compared with reference potentials 

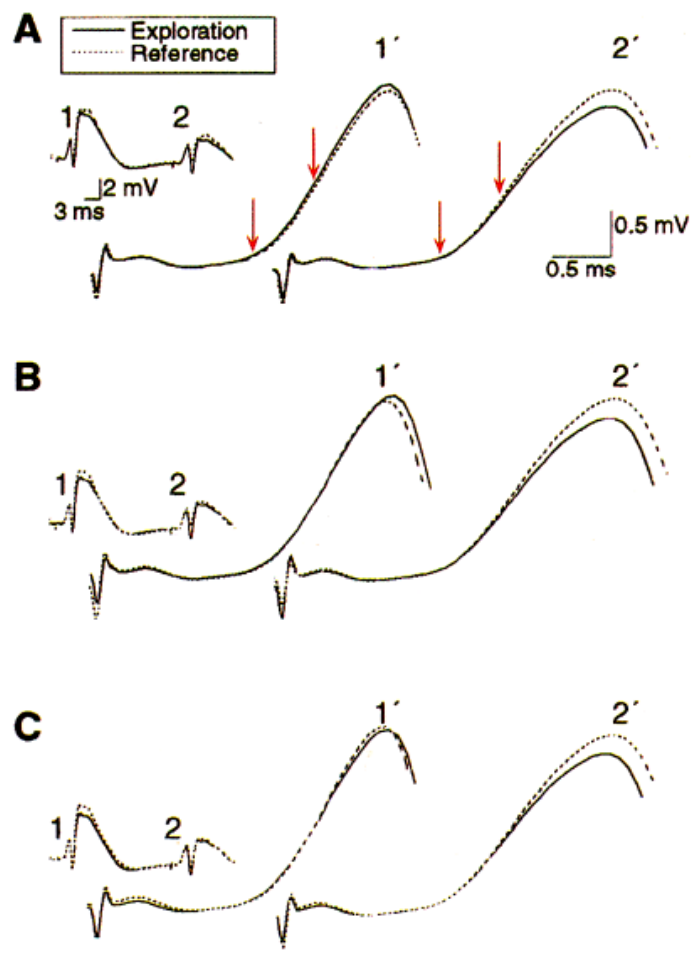
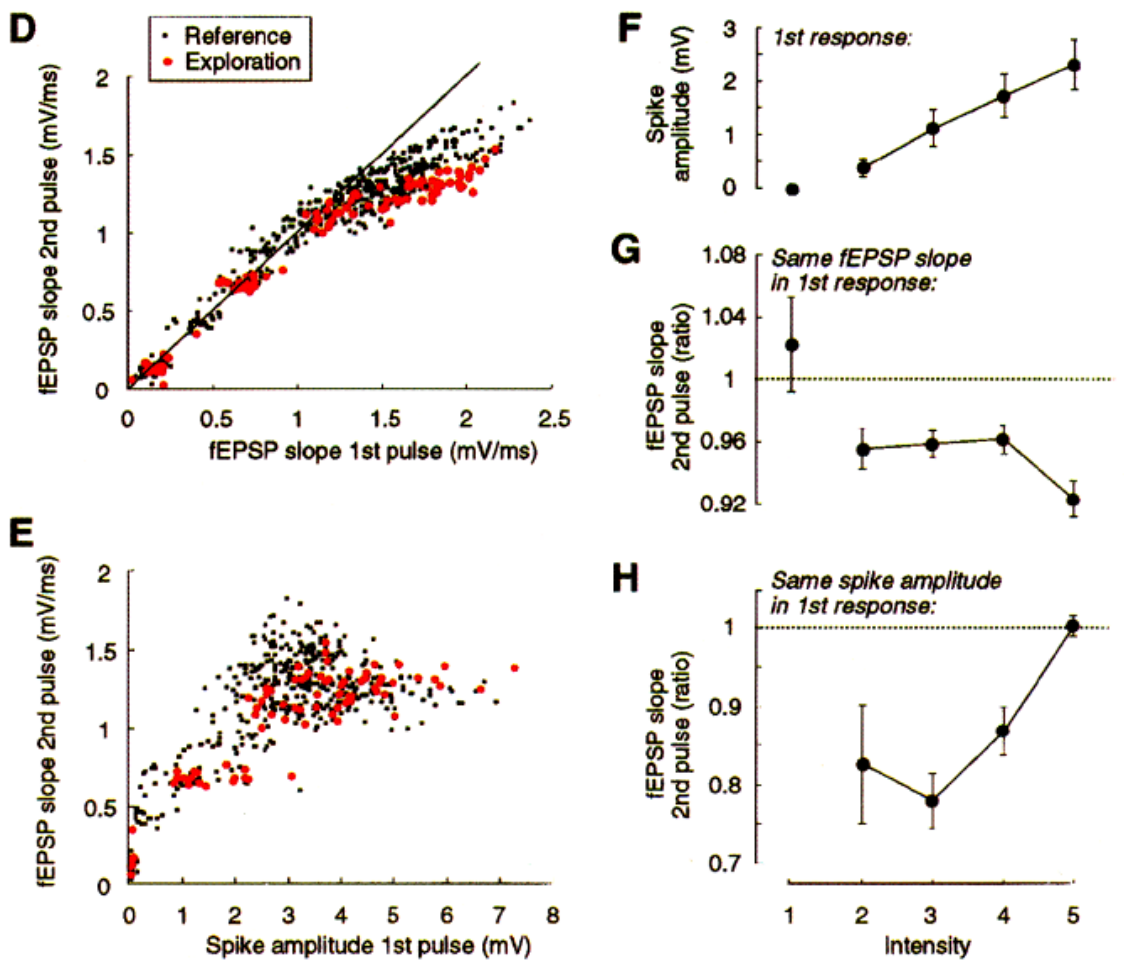

Figure 3. Suppression of the second fEPSP during exploration. $A$, Superimposed averages of pairs of potentials ( 1 and 2$)$ taken during the first minutes of an exploration episode (solid line) or at the same brain temperature in the reference task (stippled line). A population spike was evoked consistently in the conditioning response. The early rising parts of the first (1) and the second (2) responses are magnified $\left(1^{\prime}\right.$ and $2^{\prime}$, respectively) to the right. Vertical arrows indicate positions for fEPSP slope measurement. $B$, Similar to $A$, but the stippled lines represent the averages of temperature-matched reference pairs in which the fEPSP slopes of the first response were similar to the fEPSP slope of the averaged first response during exploration. $C$, Similar to $A$, except that the stippled lines represent the averages of reference potentials in which the first response had a population spike amplitude (rather than fEPSP slope) similar to the averaged first response of the exploration period. Note that the reduction of the fEPSP slope of the test potential $\left(2^{\prime}\right)$ also is present in $B$ and $C . D, E$, Suppression of the slope of the second fEPSP as a function of the fEPSP slope $(D)$ or the spike amplitude $(E)$ of the first response (unaveraged data). The data are from an experiment in which the stimulation was varied continuously among five levels of pulse intensity during exploration (same experiment as $A-C$ ). Reference data (black) are taken from input-output series conducted at the end of the resting sessions, when the brain temperature was low and changed at a slow rate. The exploration data (red) were sampled during the first minutes of the exploration session, when the brain temperature still was within the temperature range of the input-output recordings in the control sessions. Test fEPSPs of the same magnitude as the conditioning fEPSPs fall on the straight line in $D$. The spike threshold was reached at an fEPSP slope of $\sim 0.5 \mathrm{mV} / \mathrm{msec}$ in the first response. $F-H$, Average data showing relationship between stimulation intensity and suppression of the slope of the second fEPSP in experiments in which the pulse intensity was varied continuously among five intensity levels during exploration. Intensity 1 always was below the threshold for a population spike in the first response; intensities 2-5 gave population spikes of increasing amplitude. $F$, Mean amplitude ( \pm SEM) of the population spike elicited in the first potential at each intensity. $G$, Relationship between intensity level and fEPSP slope of the second waveform during the first minute of exploration. The test fEPSP slope is expressed as a fraction of the test fEPSP slope of reference pairs with a similar fEPSP slope value in the first response. $H$, Similar to $G$, but with the fEPSP slope of the second pulse expressed as a ratio of reference potentials with similar population spike amplitudes in the first response. Reference potentials were temperature-matched in both $G$ and $H$.

recorded at a similar brain temperature when the rat was resting in its home cage inside a black, shielded chamber.

As reported previously (Moser et al., 1993b, 1994), exploration was associated with an enhanced fEPSP slope of unconditioned dentate field potentials (Fig. $3 A$ ). Test potentials collected during exploration, therefore, were compared with the subset of temperature-matched reference potentials for which the conditioning responses had similar fEPSP slope values (average difference, $<0.1 \%)$.

\section{The fEPSP of the test response is reduced more during exploration}

During exploration, the suppression of the test fEPSP slope compared with the conditioning fEPSP slope was enhanced. The test fEPSP slopes of potentials sampled during exploration were reduced more than those of reference potentials sampled at a similar brain temperature with a similar fEPSP slope in the conditioning response (Fig. $3 B$ ). However, the suppression re- quired that a population spike be elicited by the first stimulus, and the effect was expressed only if there also was some fEPSP reduction at the same intensity in the reference condition (Fig. $3 D$ ). At lower conditioning strengths, the test fEPSP did not differ in the exploration and resting conditions. ANOVA comparing the test fEPSP slopes elicited at each intensity during exploration with reference test fEPSP slopes of pairs with a similar conditioning fEPSP slope (mean fEPSP slope difference, $<0.1 \%$ ) revealed a significant task $\times$ intensity effect for the data in Figure $3 D$ $\left(F_{(4,240)}=2.98, p<0.05\right)$. The analysis applies to the initial 3-4 min of exploration, for which temperature-matched control responses with conditioning fEPSPs of similar magnitude were available.

Similar results were observed when the experiments were averaged (Fig. 3G). Intensities below the population spike threshold were not associated with a decrease of the test fEPSP slope (mean change $\pm \mathrm{SEM},+2.0 \pm 3.0 \%)$. In all categories above the spike 
threshold, however, the test fLPSP slope was reduced significantly relative to temperature-matched reference potentials with a nearly identical fFPSP in response to the first stimulus $(-5.9 \pm$ $\left.0.4 \%, t_{(7)}=4.3, p<0.001\right)$. The suppression did not increase significantly with elevated pulse intensity $\left(F_{(3,21)}=1.69, p>0.05\right.$; suprathreshold intensities only). The accuracy of the temperature matching did not differ below and above the spike threshold (average error, $<0.08^{\circ} \mathrm{C}$ ).

Exploration suppressed the fEPSP of the test response also when the amplitude of the conditioning population spike was similar in the two conditions (Fig. $3 C$ ). In the resting condition, the test fEPSP slope generally increased with increasing spike amplitude in the first response, although population spikes of $>3 \mathrm{mV}$ were not associated with additional enhancement of the test fEPSP slope (Fig. $3 E$ ). During exploration, the test $\mathrm{E} E \mathrm{PSP}$ slopes were smaller, except at intensities for which no population spike was elicited or for which the test fLPSP was maximal (population spikes of $>4 \mathrm{mV}$ ). ANOVA of the data in Figure $3 E$ showed significant effects of Task $\left(F_{(1,240)}=\right.$ $12.9, p<0.001)$ and task $\times$ intensity $\left(F_{(4,240)}=8.47, p<0.001\right)$. Comparisons across experiments were made by expressing the fEPSP slope of the test response during exploration as a fraction of the test fEPSP slope of reference pairs with a similar population spike amplitude (average difference, $<0.5 \%$ ) in response to the first volley (Fig. 3H; initial 3-4 min only). These analyses showed an overall reduction of the mean test fEPSP slope of $13.1 \pm 3.0 \%$ during exploration $\left(t_{(0)}=4.41, p<0.001\right)$, although there was no suppression at the highest intensity (intensity effect, $F_{(3,21)}=5.95, p$ $<0.005)$.

A similar discharge-dependent fEPSP reduction was observed in three exploration experiments in which the test stimulus was kept constant while the strength of the conditioning pulse was varied. Below the threshold for a population spike in the first response (threc intensity levels), the test fEPSP slope increased between 11 and $19 \%$ during exploration (means of initial $3 \mathrm{~min}$ ) compared with temperature-matched reference values. At an intensity slightly above the threshold, the mean increase was reduced to $4.9 \%$. At the strongest intensity, the test fEPSP slope decreased in all cases (mean, $-23.7 \%$ ).

Experiments in which the interstimulus interval was varied $(n=$ 3) showed that test fEPSPs recorded during exploration were reduced compared with the reference test potentials only at intervals in which some attenuation also was observed in the control condition. The additional suppression in the exploration condition was $17.5 \%$ at $10 \mathrm{msec}$ and $22.4 \%$ at $20 \mathrm{msec}$ (means, suppression in three of three cases). There was no consistent change at 100 msec (mean change, $+8.4 \%$ ).

\section{The population spike of the test response is facilitated during exploration}

In the control condition, the population spike of the test response was suppressed significantly compared with the spike of the conditioning response (Fig. 4). This suppression was weaker during exploration. Compared with temperature-matched reference potentials, the test population spike of an exploring rat was enhanced across nearly the entire range of test fEPSP slope values (Fig. $4 E, H$ ). On average, the amplitude of the population spike of the test potential increased by $65.1 \pm 16.8 \%$ (mean \pm SEM of intensities evoking a population spike; $t_{(7)}=3.9 ; p<0.01$ ) compared with reference potentials with a similar test fEPSP slope (average slope difference, <0.1\%).

The enhanced fEPSP-spike relationship was specific to the second potential. The mean change in the first response was only
$1.8 \pm 7.5 \%$, but the effect was greater at maximal stimulation intensities (Fig. 4D, $G$ ). ANOVA including the four intensities above the spike threshold showed a significant effect of intensity for the first (but not the second) response $\left(F_{(3,21)}=14.6, p<\right.$ 0.001 ).

As with the fEPSP slope reduction, the facilitation of the test population spike appeared to be specific to short interstimulus intervals $(n=3)$. There was a consistent increase at $20 \mathrm{msec}$ (mean change, $+34 \%$ ), but no reliable change at $100 \mathrm{msec}$ $(-16 \%)$. The effect could not be determined at $10 \mathrm{msec}$ (no population spike in the test response).

\section{Relationship between changes in test fEPSP and test population spike}

The exploration-related facilitation of the test population spike was independent of the reduction of the test fEPSP. There was no significant corrclation at any pulsc intensity (correlation between mean changes across four intensities: $r_{(6)}=0.05, p>0.05$ ) (test spike amplitude: ratio of reference potentials with a similar test fEPSP slope, and test fEPSP slope: ratio of reference potentials with a similar fEPSP slope in the first response).

\section{The suppression of the test fEPSP decays}

To determine the time course of the changes in paired potentials, the means of the values recorded during each 1 min block of the exploration session were compared with potentials taken at the closest possible brain temperature in the resting condition. Because the pulse intensity was not varied during the highest brain temperatures in the reference condition (when the temperature dropped rapidly), corrections for differences in the size of the conditioning potentials could not be made for the later parts of the exploration test. However, the difference in reduction of the test fEPSP caused by increasing conditioning fEPSPs from the reference condition to the magnitude of conditioning fEPSPs recorded at similar brain temperature during the early phase of exploration was small $\left(-1.3 \pm 1.1 \%, t_{(20)}=1.2, p>0.05\right)$, suggesting that a possible overestimate does not invalidate the estimated time course of the fEPSP suppression.

With the matching procedure (see above), the suppression of the test fEPSP slope appeared to be greater at the start of the exploration session (Figs. 5, 6A). The suppression was fairly constant during the first $5 \mathrm{~min}$, when the paired-pulse ratio was reduced by $6-6.5 \%$. The reduction then decayed to $3-4 \%$ at the termination of the exploration (time effect: $F_{(14,364)}=4.10, p<$ $0.001)$. The ratio did not change with time in experiments in which no population spike was evoked $\left(F_{(14,154)}=1.03, p>0.05\right.$; Fig. $6 B)$.

During the first minute of the exploration session, fEPSPs usually could be compared with reference potentials matched for both brain temperature and fEPSP slope of the first response (average difference, $<0.15 \%$ ). As in the other experiments analyzed in this way (Fig. 3), there was an increased suppression of the test fEPSP during exploration (paired-pulse ratio, $-4.1 \pm$ $1.5 \%, t_{(20)}=2.73, p<0.02$ ), provided that a population spike was elicited by the first pulse (Fig. $6 A, C$ ). When the first volley failed to evoke a population spike (Fig. $6 B$ ), the sccond fEPSP was not altered (paired-pulse ratio, $+1.2 \pm 1.7 \%, p>0.05$; difference from suprathreshold experiments: $t_{(37)}=4.10, p<0.001$ ). Above the spike threshold, the test fEPSP suppression increased with increasing pulse intensity (Fig. 6C) (correlation between conditioning spike amplitude and test fEPSP slope suppression: $r_{(19)}=$ $0.481, p<0.05$; suprathreshold experiments only). The suppres- 
A

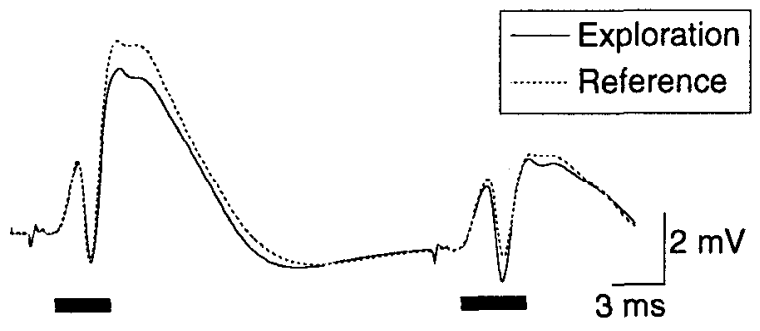

C

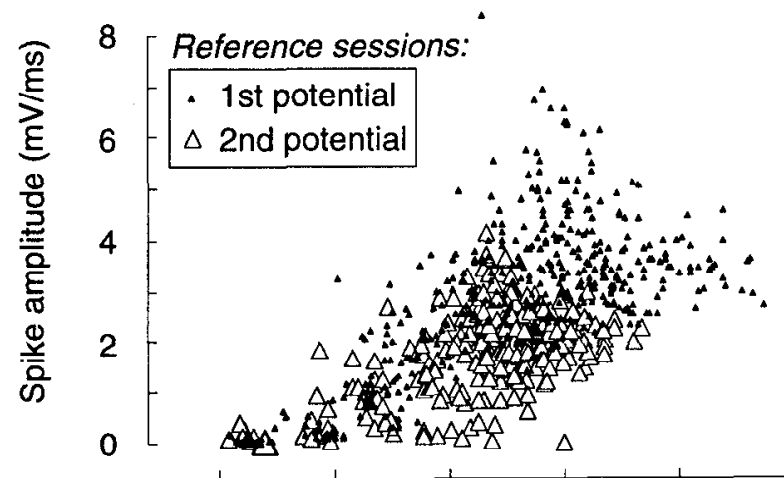

D
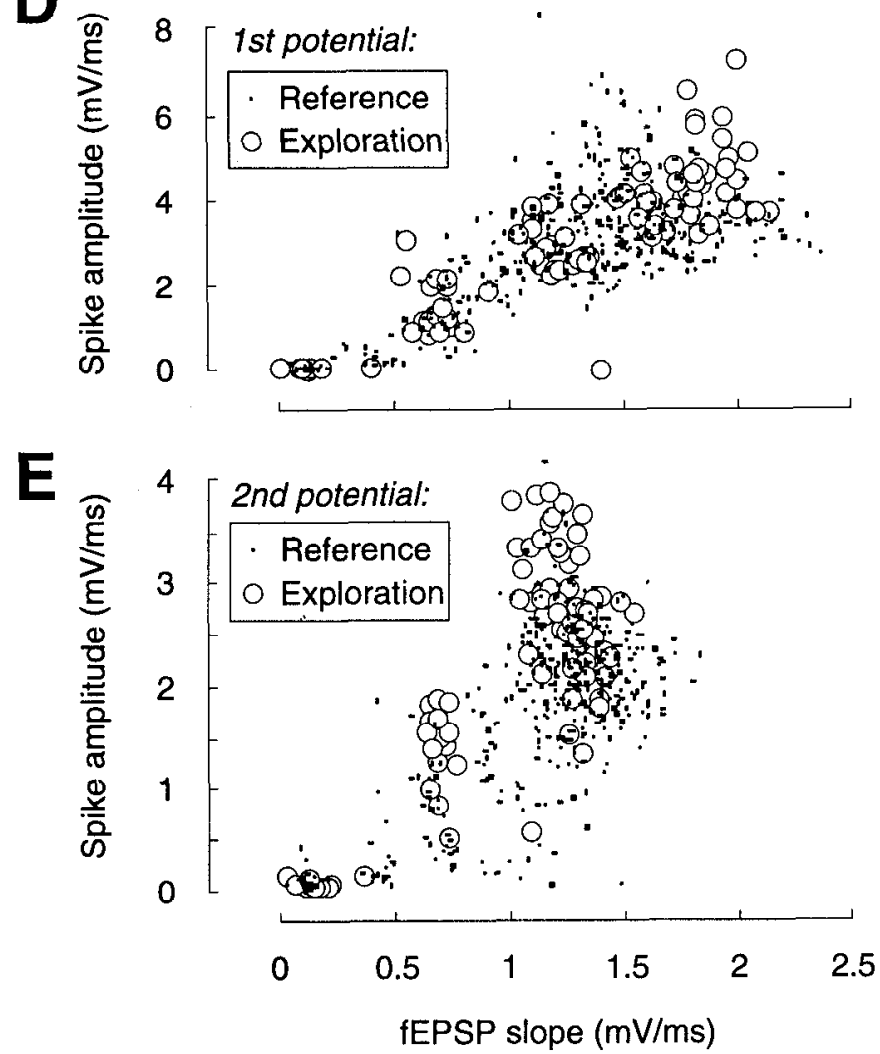

B

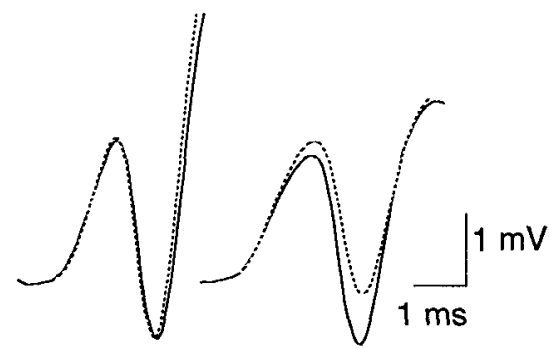

$\mathbf{F}$

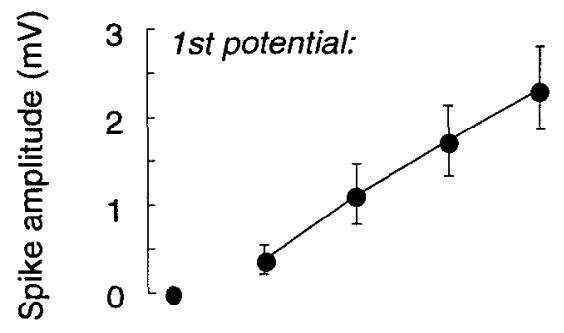

G

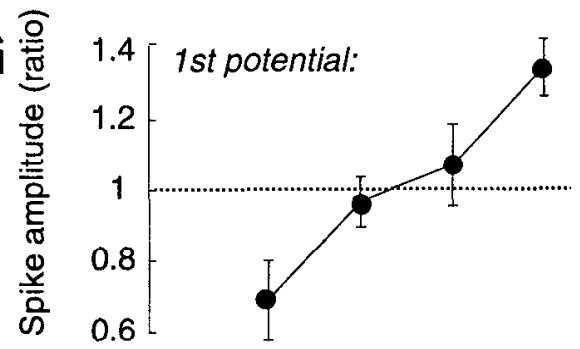

H

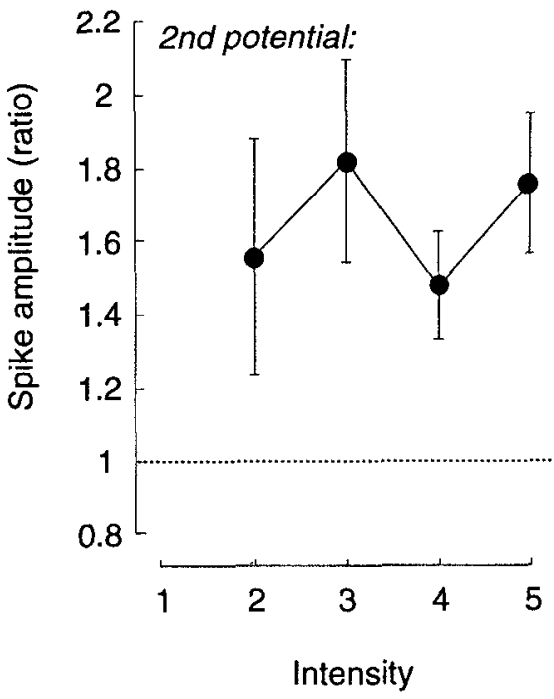

Figure 4. Facilitation of the population spike of the second response during exploration. $A$, Superimposed averages of pairs of potentials sampled during the first minutes of an exploration episode (solid line) or at the same brain temperature in the reference task (stippled line). $B$, Magnification of the early parts (indicated by black bars in $A$ ) of these responses. $C$, Relationship between IEPSP slope and population spike amplitude for the first (filled triangles) and the second (open triangles) response in the reference condition (representative experiment). $D, E$, Effect of exploration on the relationship between fEPSP slope and spike amplitude in the first $(D)$ and the second $(E)$ waveform (same experiment as in $C$ ). $F-H$, Average of experiments for which the pulse intensity was varied continuously among five intensity levels during exploration. Intensity $l$ always was below the threshold for a population spike in the first response; intensities 2-5 gave population spikes of increasing amplitude. $F$, The spike amplitude of the first response during the exploration episode (mean $\pm \mathrm{SEM}) . G, H$, Spike amplitude of the first $(G)$ or the second $(H)$ potential during exploration, expressed as a ratio of the mean spike amplitude of temperature-matched reference pairs with a similar fEPSP slope in the first $(G)$ or the second $(H)$ response. 


\section{EXPLORATION}
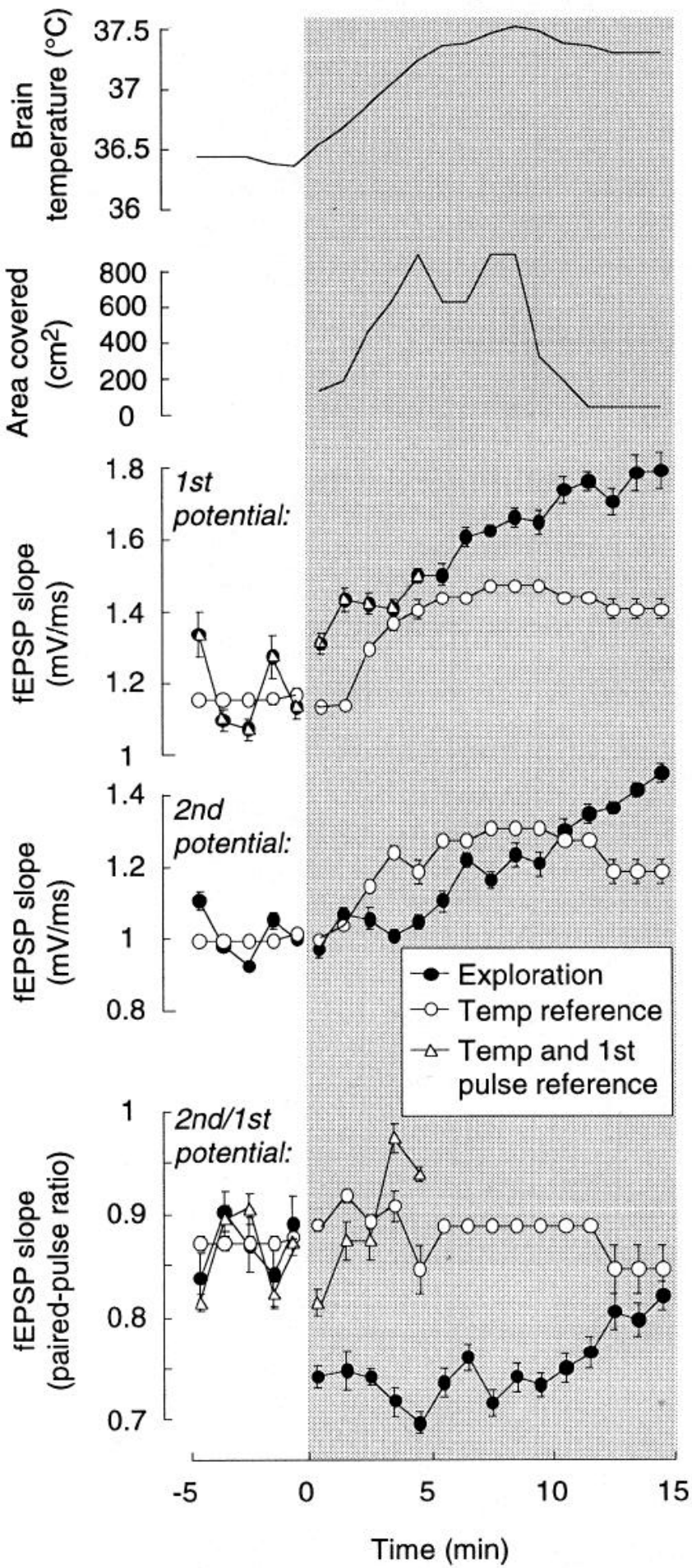

Figure 5. Comparison of pairs of field potentials sampled during exploration and at the same brain temperature $\left( \pm 0.04^{\circ} \mathrm{C}\right)$ in a resting condition (single experiment). Stimulation evoked a population spike in the first response. The brain temperature, the area covered, the fEPSP slope of the first and the second waveform, and the ratio between the slope values of the two responses (2nd/1st potential) are shown for blocks of 1 min during exploration (shaded area) and during the resting baseline condition (mean $\pm \mathrm{SEM}$; filled circles). Open circles indicate mean values $( \pm$ SEM) of potentials sampled in the reference condition at a similar temperature (not chronological). Triangles (1st potential and 2 nd/1st potential) show temperature-matched reference potentials in which the fEPSP slope value of the first response was similar to that of the first response in the exploration condition. sion during exploration also depended on the amount of suppression at the test intensity in the reference condition (paired-pulse ratio at test intensity-paired-pulse ratio at lowest subthreshold intensity: $r_{(19)}=0.56, p<0.01$ ). Cases with no suppression in the control task failed to show suppression of the test fEPSP during exploration (mean change, $+3.1 \% ; n=4$ ). Taken together, these correlations suggest that the more interneurons were discharged by the granule cells, the greater the inhibition of the test fEPSP was during the early minutes of the exploration session.

Some of the difference between records taken below and above the spike threshold could be attributable to differences in the conditioning response. However, the increase in the unconditioned fEPSP compared with temperature-matched reference values (Moser et al., 1994) was similar in experiments conducted with and without a population spike in the first response $(7.7 \pm 1.2$ and $9.0 \pm 2.3 \%$, respectively; difference: $\left.t_{(37)}=0.55, p>0.05\right)$. The enhancement was greatest during the first minute of exploration in both cases $(11.3 \pm$ 1.3 and $17.9 \pm 3.9 \%$, respectively; time effects: $p<0.01)$. Supra- and subthreshold experiments also were comparable with respect to the intensity of exploration $\left(257.4 \pm 19.8\right.$ and $271.6 \pm 44.7 \mathrm{~cm}^{2}$, respectively; $t_{(36)}=0.34 ; p>0.05$; Fig. $\left.6 A, B\right)$. The mean accuracy of the temperature-matching (mean difference between the temperatures associated with potentials recorded during exploration and matched reference potentials) was $0.006^{\circ} \mathrm{C}$.

\section{The facilitation of the test population spike is stable}

Estimates of the time course of the population spike facilitation were based on comparisons of the spike amplitude-fEPSP slope ratio of each potential during exploration and at similar brain temperature in the resting condition. The ratio is sensitive to increases in the first potential during exploration, but the effect of an fEPSP slope enhancement of $10-20 \%$ in the first potential is marginal (Fig. $4 C$ ), suggesting that the procedure gives a reasonable estimate of the time course.

The analyses showed that the facilitation of the test population spike was maintained throughout the exploration task (Fig. 7). The fEPSP-spike relationship in the early part of the exploration was enhanced for both the conditioning and the test responses, but with a larger increase for the latter (first response, $8.7 \pm 7.8 \%$; second response, $59.3 \pm 18.2 \%$; difference: $\left.t_{(32)}=2.6, p<0.02\right)$. Whereas the population spikefEPSP slope ratio of the first potential decayed slowly $\left(F_{(14,224)}\right.$ $=1.92, p<0.05)$, the relative facilitation of the test population spike showed a slight increase in the middle of the session (time effect: $\left(F_{(14,224)}=1.93, p<0.05\right)$. The exploration intensity (area covered/min) did not change significantly over time $\left(F_{(14,224)}=1.73, p>0.05\right)$, and the temperature-matching was accurate throughout the session (mean difference, $0.009^{\circ} \mathrm{C}$ ).

The facilitation of the population spike of the test response (compared with the fEPSP slope) correlated neither with the spike amplitude of the first response $\left(r_{(15)}=0.24\right)$ nor with the suppression of the test fEPSP $\left(r_{(15)}=-0.27, p>0.05\right)$.

\section{The test potential changes are not related to the amount of motor activity}

The exploration-induced suppression of the test potential may be related to the level of motor activity and the tightly associated hippocampal theta rhythm (Vanderwolf, 1969). Thus, the median value of the area/min measure was calculated for the entire set of experiments. For each experiment, the field potential values of each 1 min block of the exploration session then were divided into two categories: signals taken in blocks when the rat covered an 
A

\section{ABOVE SPIKE THRESHOLD:}

EXPLORATION
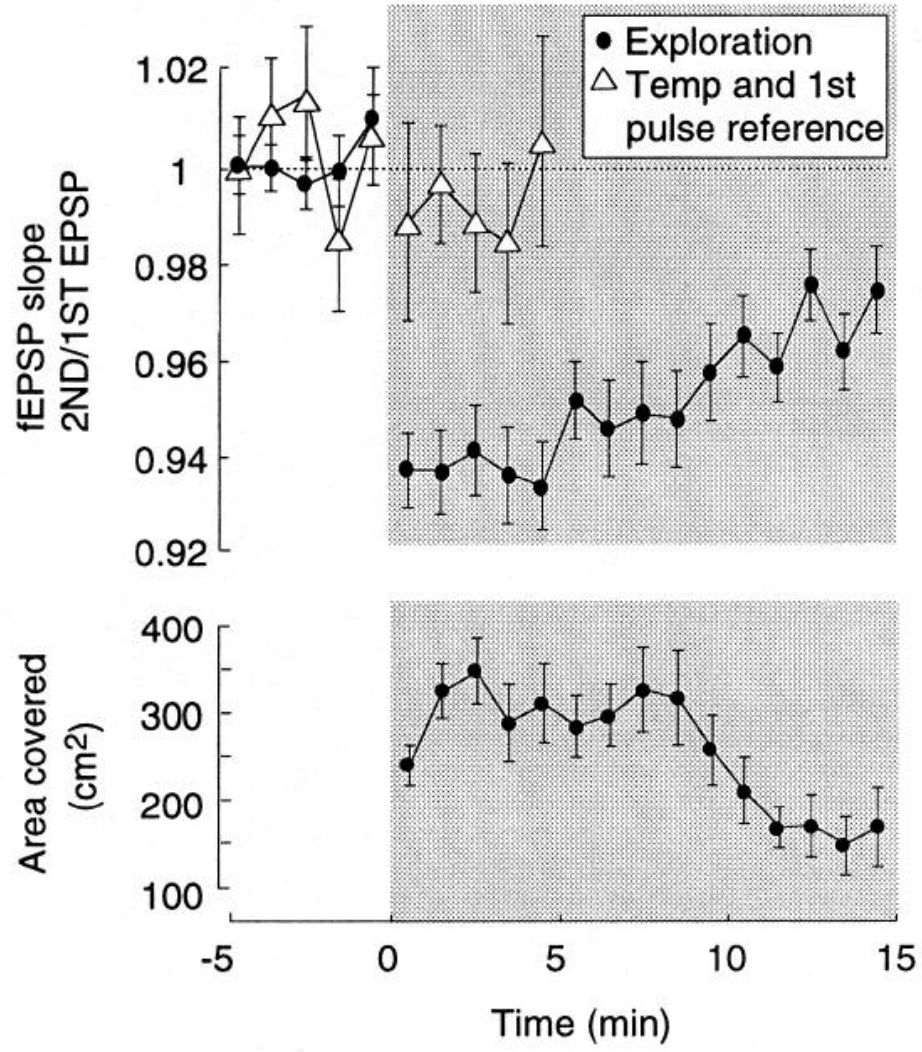

B BELOW SPIKE THRESHOLD:

EXPLORATION
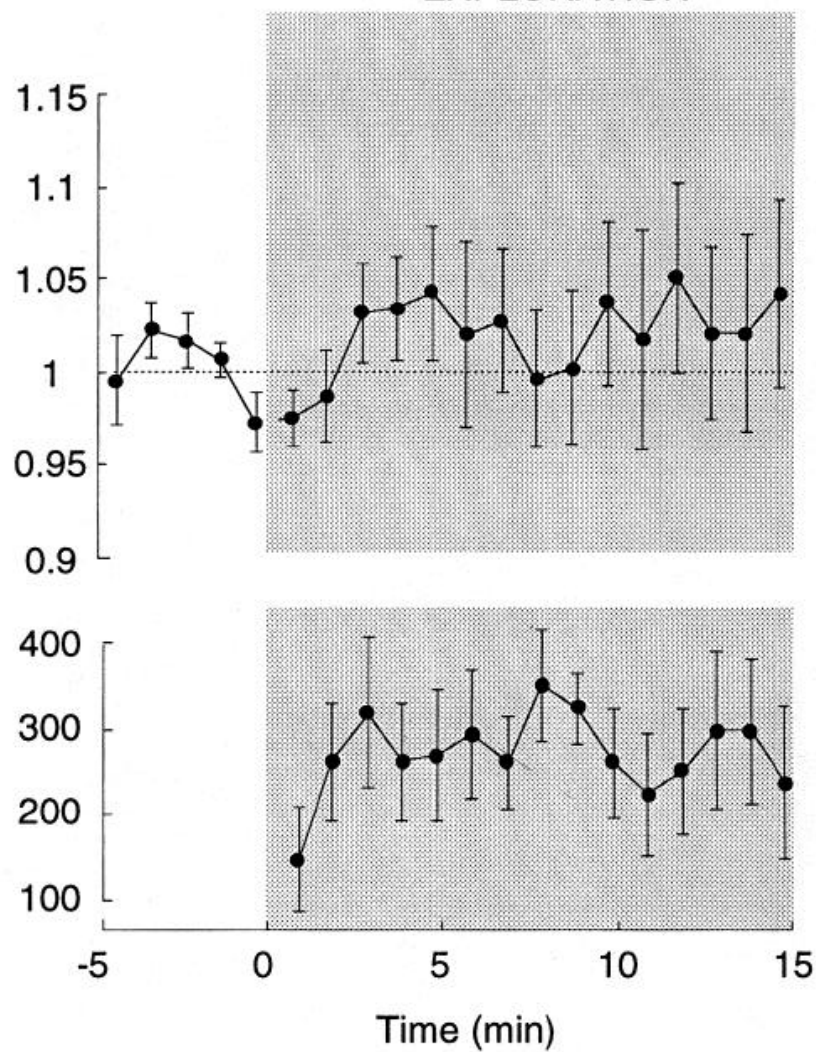

C

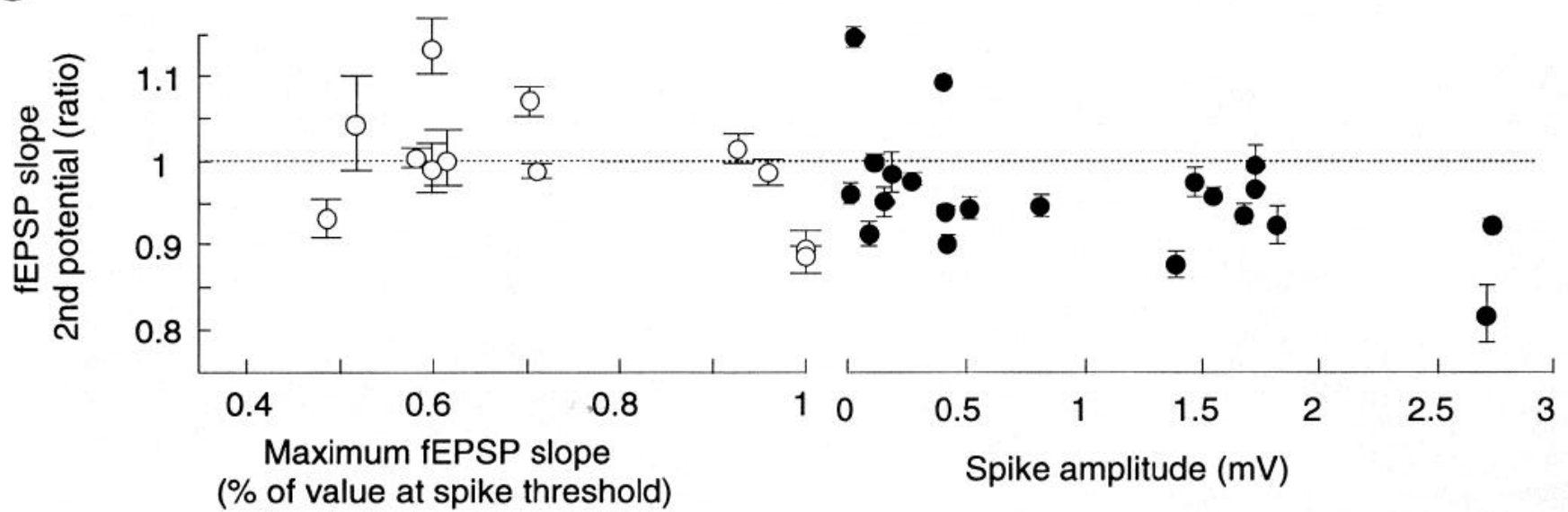

Figure 6. Average time course of changes in paired-pulse ratio (fEPSP slope 2ND/1ST EPSP) during exploration (shaded area). A, Experiments in which the stimulation intensity was sufficiently high to elicit a population spike in the first response. The ratio between the fEPSP slopes of the second and the first response is shown as a function of time, with the data grouped into blocks of 1 min (mean \pm SEM) and expressed as a ratio of the mean value of potentials recorded at a similar brain temperature $\left( \pm 0.04^{\circ} \mathrm{C}\right)$ in the reference situation. Open triangles show comparisons in which the potentials recorded during exploration have been exchanged with temperature-matched reference potentials having similar fEPSP slopes in response to the first pulse. Area covered/min also is indicated. $B$, Similar to $A$, but at stimulation intensities that failed to evoke a population spike in the conditioning potential. $C$, Relationship between intensity of stimulation and suppression of the fEPSP slope of the second response during exploration. The test fEPSP slope is expressed as a fraction of the value recorded at similar brain temperature in reference pairs with responses of similar magnitude (fEPSP slope) to the first volley. Below the threshold for a population spike in the first potential, pairs are sorted according to the magnitude of the maximum rising fEPSP slope of the first response during baseline recording (open circles). This value is expressed as the percentage of the maximum fEPSP slope at the spike threshold. Above the threshold (filled circles), potentials are sorted according to the amplitude of the population spike of the conditioning potential. Each circle represents the mean value $( \pm \mathrm{SEM})$ of the first $5 \mathrm{~min}$ of the exploration test. 
A
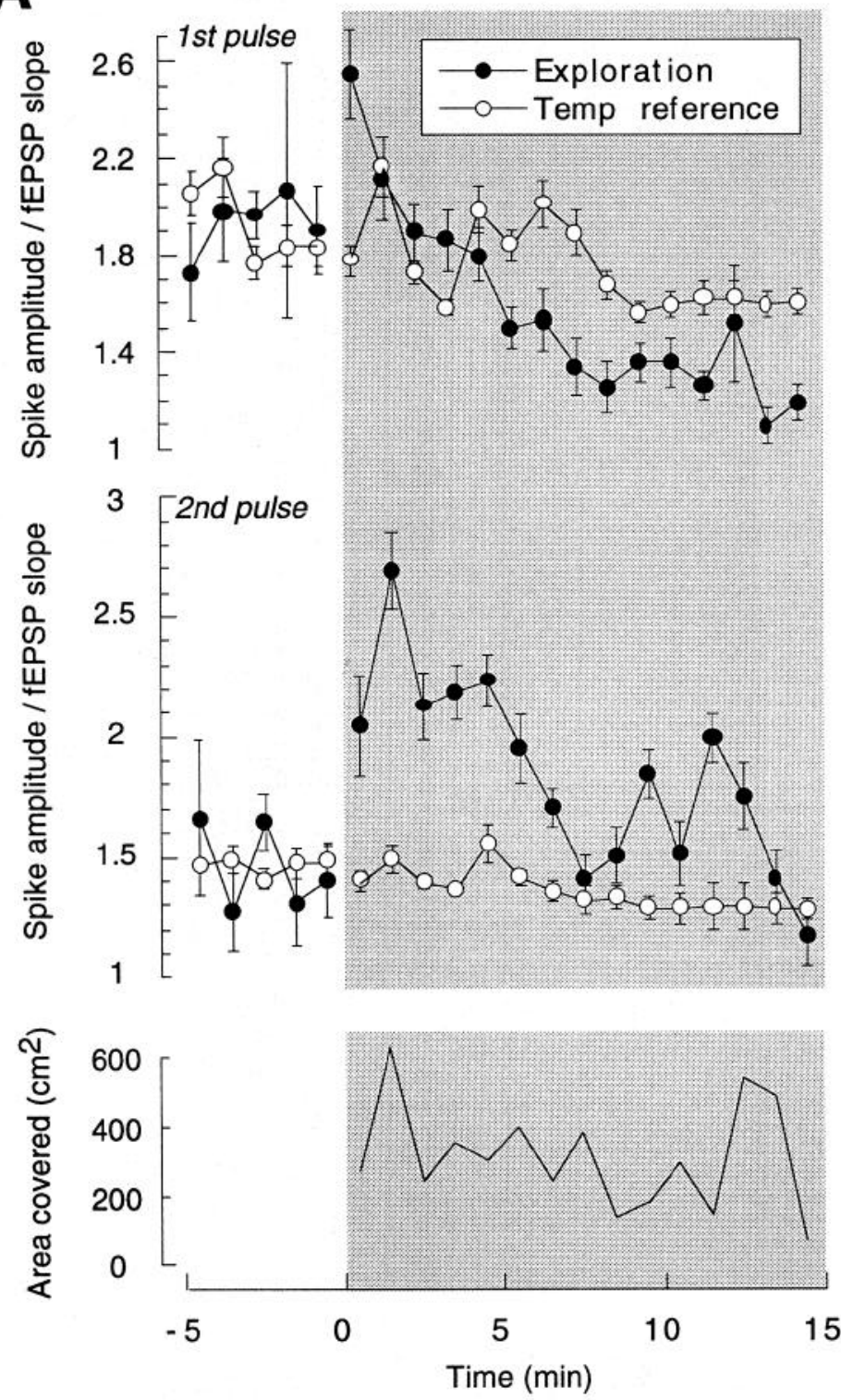

B
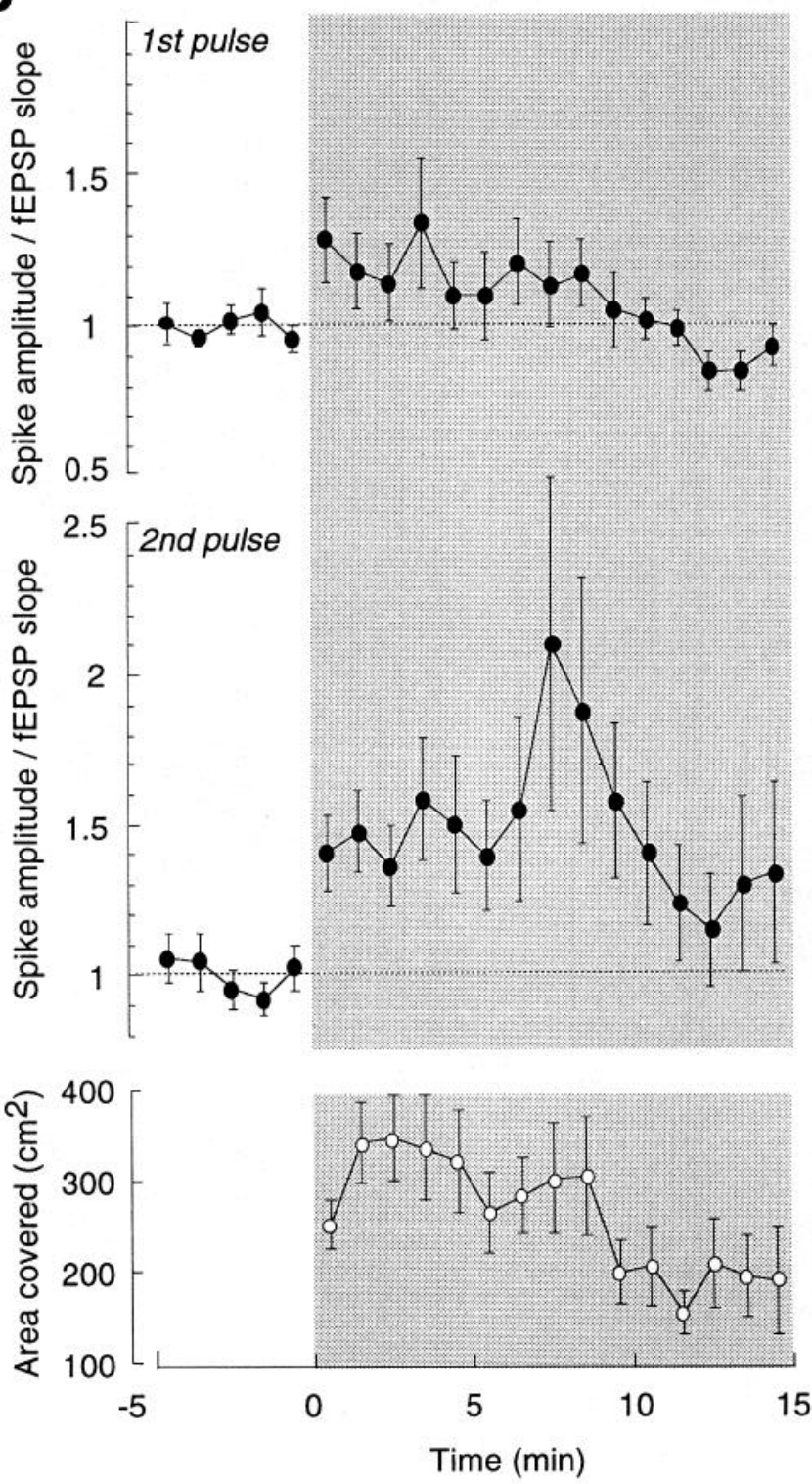

Figure 7. Changes in population spikes of paired potentials during exploration. A, Single experiment. The spike amplitude-fEPSP slope ratios of the first and the second waveform, as well as the area covered, are shown for blocks of $1 \mathrm{~min}$ (mean $\pm \mathrm{SEM}$ ). Values of potentials recorded during the 5 min baseline period and the subsequent $15 \mathrm{~min}$ exploration session (shaded area) are indicated by filled circles. Open circles indicate the means ( \pm SEM) of potentials sampled in the reference condition at a similar temperature (not chronological). $B$, Average of all experiments. The values of each 1 min block are expressed as ratios of the corresponding values of reference potentials recorded at a similar brain temperature.

area smaller than the group median value $\left(117 \pm 8 \mathrm{~cm}^{2} / \mathrm{min}\right)$, and signals taken in periods when the rat covered a larger area (455 \pm $20 \mathrm{~cm}^{2} / \mathrm{min}$ ). To allow sampling from the entire exploration session, potentials from the exploration and reference sessions were matched only with respect to temperature.

The slope of a single fEPSP is reduced by motor activity (Green et al., 1990; Moser et al., 1994). In the present study, the fEPSP slope of the first response was increased by $10.0 \pm 0.5 \%$ compared with temperature-matched reference potentials in the low-activity condition, but only $5.3 \pm 0.6 \%$ during high activity. The fEPSP slope of the second response was increased $4.4 \pm 0.4 \%$ during high activity, but decreased $0.3 \pm 0.5 \%$ during low activity. The decrease of the paired-pulse ratio ( $2 \mathrm{nd} / 1 \mathrm{st}$ fEPSP slope) was similar at low $(-5.3 \pm$ $0.6 \%)$ and high levels of movement $\left(-5.0 \pm 1.1 \%\right.$; difference: $t_{(47)}=$
$0.25, p>0.05$; Fig. 8). Motor activity also failed to alter the facilitation of the spike amplitude-fEPSP slope ratio of the test response (high activity, $+73.7 \pm 26.5 \%$; low activity; $+34.1 \pm 18.2 \%$; difference: $\left.t_{(30)}=1.23, p>0.05\right)$. The brain temperature matching of the data sets did not differ (mean differences, $0.005^{\circ} \mathrm{C}$ ). Thus, it is unlikely that the alterations in the test response are related to variations in the activity level of the rats.

\section{DISCUSSION}

Exploration was associated with increased suppression of the fEPSP and decreased suppression of the population spike evoked by the second of a pair of stimuli to the perforant path. The decrease of the test fEPSP slope may be attributable to an increase in inhibition on the perforant-path terminals or the dendrites of the granule cells, 
A

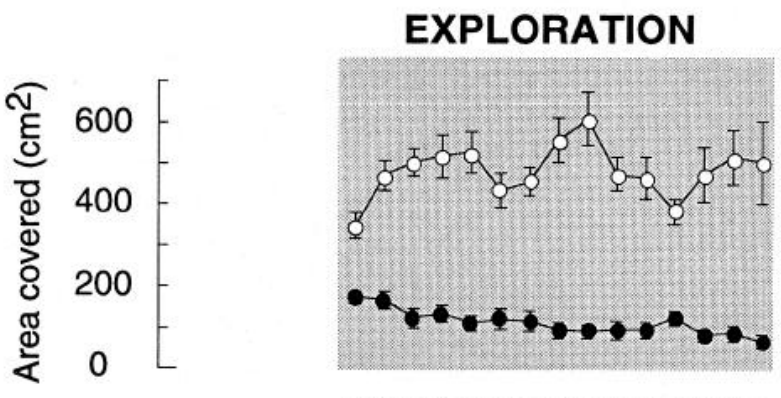

B
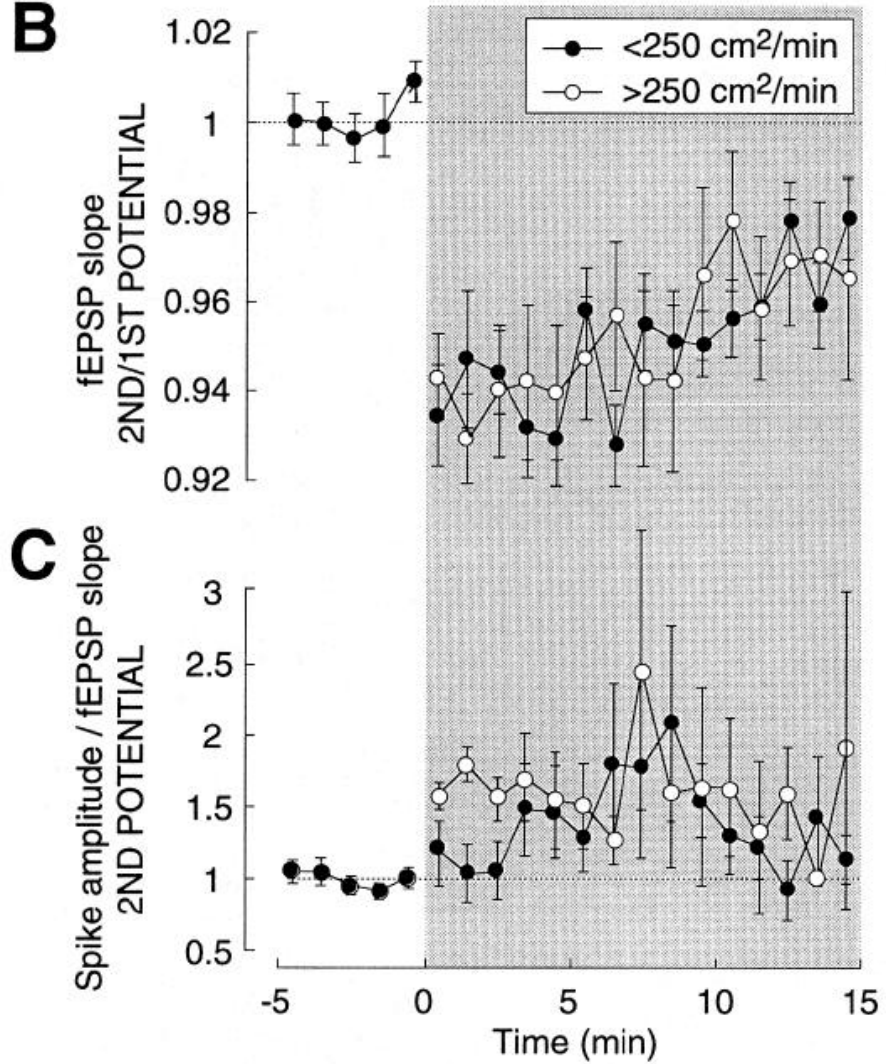

Figure 8. Effect of motor activity on paired potentials recorded during exploration, averaged across experiments. The area covered, the ratio between the fEPSP slopes of the second and the first potential, and the spike amplitude-fEPSP slope ratio of the second response are shown for each 1 min block of the exploration session (shaded area) and for the preceding baseline period. Data recorded at speeds above and below 250 $\mathrm{cm}^{2} / \mathrm{min}$ are displayed separately. All of the data are expressed as ratios of the corresponding values of potentials recorded at a similar temperature in the resting session (see Fig. 6).

whereas the relative facilitation of the test population spike likely reflects a decrease in inhibition proximal to the somata of the granule cells. The changes in fEPSP and population spike of the test response were not correlated and followed different time courses. The fEPSP suppression decayed, whereas the spike facilitation was stable. Thus, dendritic and somatic inhibition of dentate granule cells may be regulated independently during exploration.

\section{Interpretation of test response changes in the control condition}

The present data do not show directly that suppression of the test response (fEPSP slope and population spike amplitude) in the control condition is attributable to recurrent inhibition of the granule cells. The interpretation is plausible, however, for the following reasons: (1) the suppression was observed only with a population spike in the first response; (2) the magnitude of the suppression followed the amplitude of the population spike; and (3) the duration was within the time window of granule cell IPSPs (Andersen et al., 1966; Fournier and Crepel, 1984). Dischargedependent suppression of the test fEPSP was not observed in anesthetized rabbits by Lømo (1971), but it appears to have been recorded previously in chronically implanted rabbits (Bliss and Gardner-Medwin, 1973; their Fig. 1a) and anesthetized rats (Steward et al., 1976).

In an anatomical context, it is not surprising that the test fEPSP was reduced. The axons of many dentate and hilar interneurons ramify preferentially in the perforant-path terminal field of the molecular layer, where they establish synapses with the granule cell dendrites (Bakst et al., 1986; Leranth et al., 1990; Halasy and Somogyi, 1993; Han et al., 1993; Buckmaster and Schwartzkroin, 1995). One group of such interneurons, colocalizing GABA and somatostatin (Somogyi et al., 1984; Bakst et al., 1986), constitutes as much as $30 \%$ of the hilar interneuron population in rats (Rapp and Amaral, 1988). These cells receive input from mossy fibers (Leranth et al., 1990; Baude et al., 1993) and may be part of an extensive feedback loop back to the dendrites of the granule cells. With terminals primarily on the dendritic shaft of the granule cells (Leranth et al., 1990; Halasy and Somogyi, 1993), the hilar interneurons are well positioned to shunt excitatory currents from the perforant-path synapses (Koch et al., 1983; Staley and Mody, 1992), although they also may generate large IPSPs in depolarized dendrites. The burst-like discharge of hilar interneurons after a perforant-path volley (Fox and Ranck, 1981; Buzsáki and Eidelberg, 1982) may increase the overlap between inhibitory and excitatory conductances.

\section{Interpretation of test response changes during exploration}

The increased suppression of the test fEPSP during exploration may reflect increased inhibition in the dendritic region of the granule cells. This is consistent with the following: (1) the fEPSP suppression during exploration was specific to the second potential; (2) it required a population spike in the first response; (3) it occurred only if the test fEPSP also showed some decrease compared with the first potential in the control recordings; and (4) the test fEPSP of exploring rats was reduced 10 and $20 \mathrm{msec}$, but not $100 \mathrm{msec}$, after the conditioning stimulus. Because the reference potentials were matched with respect to the amplitude of the conditioning population spike, the effect did not reflect EPSP spike potentiation within the granule cells.

The facilitation of the test population spike during exploration likely reflects decreased inhibition in the somatic region of the granule cells. Like the test fEPSP suppression, the spike facilitation was specific to the test response and was observed at $20 \mathrm{msec}$ but not at $100 \mathrm{msec}$ intervals.

The assumed changes in dendritic and somatic inhibition during exploration were not correlated with respect to magnitude or time course, which suggests that they reflect the activity of different and independent sets of interneurons-one set with terminals in the molecular layer, the other with terminals in the hilar or granule cell region. The dendritic fields of such classes of interneurons appear to be segregated (Han et al., 1993), which suggests that the two sets of interneurons are modulated by different afferent fiber systems. The present experiments do not address the origin of any modulatory fiber systems, but both subcortical fibers and the perforant-path input itself could be involved. 
It is not unlikely that the modulation of the dentate interneurons during exploration is altered tonically. Tonic changes would affect both the conditioning and the test response, but these would be suppressed equally only if a similar number of inhibitory interneurons were active at the delivery of the first and the second volleys. Because the conditioning stimulus activates a significant proportion of the interneuron population via the granule cells, a higher number of interneurons may be discharging during the second pulse. The difference in the number of firing interneurons probably is amplified by the burst-like discharge of the these cells in response to perforant-path stimulation (Fox and Ranck, 1981; Buzsáki and Eidelberg, 1982). With such a difference, it is likely that any tonic change in action potential-dependent inhibition is expressed primarily during the second volley. During the first response, positive influences might over-ride the effects of the altered inhibition and give a net potentiation (Moser et al., 1994).

Changes in afterpotentials during exploration could cause test potential alterations similar to those observed. The test fEPSP would be suppressed and the population spike would be facilitated if the discharging granule cells were depolarized during the second volley. However, afterpotentials in granule cells are brief (3-5 msec) (Fournier and Crepel, 1984) and unlikely to affect postsynaptic currents in the outer dendrites $20 \mathrm{msec}$ after discharge. The lack of correlation between the fEPSP and population spike alterations argues further against a role for global factors intrinsic to the discharging cells.

\section{Relationship with learning}

The suppression of the test fEPSP is maximal when exploration starts and decays with a half-time of $10-15 \mathrm{~min}$. Because preferential inspection of novel landniarks is limited to the first 5 min (Moser et al., 1994), the greatest suppression occurs when the learning is most intense. Therefore, the effect may reflect processes involved in forming representations of the novel environment (O'Keefe and Nadel, 1978). The time course suggests that it does not reflect movement or a state shift per se.

Facilitation of the test population spike has been reported previously during voluntary or forced movement (Austin et al., 1989; Green et al., 1993). It is uncertain to what extent novel information was acquired in these situations. In the present study, the facilitation was stable and outlasted the preferential inspection of novel landmarks, suggesting that it is not related primarily to information sampling.

\section{Theta activity}

The power of hippocampal theta rhythm has been shown previously to be relatively stable in the present exploration paradigm (Moser et al., 1993b), similar to the motor activity and the spike facilitation. The test fEPSP suppression decayed, however, suggesting that it does not depend on the presence of theta activity. Further studies are required to determine how the changes in paired potentials are related to the theta rhythm.

\section{Possible roles of altered inhibition}

The axons of many hilar interneurons diverge extensively, and each axon contacts hundreds or thousands of granule cells (Struble et al., 1978; Han et al., 1993; Buckmaster and Schwartzkroin, 1995). Thus, when impulses are transmitted from the entorhinal cortex to the granule cells, the number of inhibited granule cells (via the recurrent circuit) may be greater than the number of excited cells (via the perforant path). If this is the case during acquisition of information in a novel environment, en- hanced dendritic inhibition might operate like lateral inhibition in sensory systems: nonexcited cells are kept relatively silent, whereas the perforant path-activated cells, receiving excitation in addition to the inhibition, still respond to the strongest inputs. Thus, the enhanced inhibition might attenuate background noise and, together with the facilitation of excitatory transmission onto the granule cells (Moser et al., 1994), improve the signal-to-noise ratio for input from the entorhinal cortex.

The synaptic and dendritic effects were accompanied by a reduced suppression of discharge in the granule cells. By itself, this suppression might cause a general amplification of signals entering the dentate gyrus. However, because of the enhanced inhibition in the dendrites during the early part of the exploration episode, the effect may be limited to the strongest perforant-path signals (presumably conveying information regarding the ongoing external events). In this way, enhanced dendritic inhibition and decreased somatic inhibition together may focus and amplify incoming input from the entorhinal cortex. The enhanced discharge of selected mossy fibers may cause increased depolarization of CA3 pyramidal cells which, in turn, may cause associative modifications (Buzsáki, 1989; Zalutsky and Nicoll, 1990; Treves and Rolls, 1992).

\section{REFERENCES}

Amaral DG (1978) A Golgi study of cell types in the hilar region of the hippocampus in the rat. J Comp Neurol 182:851-914.

Andersen P, Holmqvist B, Voorhoeve PE (1966) Entorhinal activation of dentate granule cells. Acta Physiol Scand 66:448-460.

Armstrong JN, McIntyre DC, Neubort S, Sloviter RS (1993) Learning and memory after adrenalectomy-induced hippocampal dentate granule cell degeneration in the rat. Hippocampus 3:359-371.

Austin KB, Bronzino JD, Morgane PJ (1989) Paired-pulse facilitation and inhibition in the dentate gyrus is dependent on behavioral state. Exp Brain Res 77:594-604.

Bakst I, Avendano C, Morrison JH, Amaral DG (1986) An experimental analysis of the origins of somatostatin-like immunoreactivity in the dentate gyrus of the rat. J Neurosci 6:1452-1462

Baude A, Nusser Z, Roberts JDB, Mulvihill E, McIlhinney RAJ, Somogyi $\mathrm{P}$ (1993) The metabotropic glutamate receptor (mGluR1 $\alpha$ ) is concentrated at perisynaptic membrane of neuronal subpopulations as detected by immunogold reaction. Neuron 11:771-787.

Bliss TVP, Gardner-Medwin AR (1973) I ong-lasting potentiation of synaptic transmission in the dentate area of the unanaesthetized rabbit following stimulation of the perforant path. J Physiol (Lond) 232:357-374

Bliss TVP, Lømo T (1973) Long-lasting potentiation of synaptic transmission in the dentate area of the anaesthetized rabbit following stimulation of the perforant path. J Physiol (Lond) 232:331-356.

Buckmaster PS, Schwartzkroin PA (1995) Interneurons and inhibition in the dentate gyrus of the rat in vivo. J Neurosci 15:774--789.

Buzsáki G (1984) Feed-forward inhibition in the hippocampal formation. Prog Neurobiol 22:131-153.

Buzsáki G (1989) Two-stage model of memory trace formation: a role for "noisy" brain states. Neuroscience 31:551-570.

Buzsáki G, Eidelberg E (1982) Direct afferent excitation and long-term potentiation of hippocampal interneurons. J Neurophysiol 48:597-607.

Cain DP, Hargreaves EL, Boon F (1994) Brain temperature- and behavior-related changes in the dentate gyrus field potential during sleep, cold water immersion, radiant heating, and urethane anesthesia. Brain Res 658:135-144.

Conrad CD, Roy EJ (1993) Selective loss of hippocampal granule cells following adrenalectomy: implications for spatial memory. J Neurosci $13: 2582-2590$.

Creager R, Dunwiddie T, Lynch G (1980) Paired-pulse and frequency facilitation in the CA1 region of the in vitro rat hippocampus. J Physiol (Lond) 299:409-424.

Fournier F, Crepel F (1984) Flectrophysiolngical properties of dentate granule cells in mouse hippocampal slices maintained in vitro. Brain Res 311:75-86. 
Fox SE, Ranck Jr JB (1981) Elcctrophysiological characteristics of hippocampal complex-spike cells and theta cells. Exp Brain Res 41:399-410.

Green EJ, Barnes CA, McNaughton BL (1993) Bchavioral state dependence of homo- and heterosynaptic modulation of dentate gyrus excitability. Exp Brain Res 93:55-65.

Green EJ, McNaughton BL, Barnes CA (1990) Exploration-dependent modulation of evoked responses in fascia dentata: dissociation of motor, EEG, and sensory factors and evidence for a synaptic efficacy change. J Neurosci 10:1455-1471.

Halasy K, Somogyi P (1993) Subdivisions in the multiple GABAcrgic innervation of granule cells in the dentate gyrus of the rat hippocampus. Eur J Neurosci 5:411-429.

Han Z-S, Buhl E, Lorinczi Z, Somogyi P (1993) A high degree of spatial sclectivity in the axonal and dendritic domains of physiologically identified local-circuit neurons in the dentate gyrus of the rat hippocampus. Eur J Neurosci 5:395-410.

Hodgkin AL, Katz B (1949) The effect of temperature on the electrical activity of the giant axon of the squid. J Physiol (Lond) 109:240-249.

Jarrard L (1993) On the role of the hippocampus in learning and memory in the rat. Behav Neural Biol 60:9-26.

Katz B, Milcdi R (1965) The effect of temperature on the synaptic delay at the neuromuscular junction. J Physiol (Lond) 181:656-670.

Katz B, Milcdi R (1968) The role of calcium in neuromuscular facilitation. J Physiol (Lond) 195:481-492.

Koch C, Poggio T, Torre V (1983) Nonlinear interactions in a dendritic tree: localization, timing, and rolc in information processing. Proc Natl Acad Sci USA 80:2799-2802.

Leránth C, Malcolm AJ, Frotscher M (1990) Afferent and eflerent synaptic connections of somatostatin-immunoreactive neurons in the rat fascia dentata. J Comp Neurol 295:111-122.

Lomo $T$ (1971) Potentiation of monosynaptic EPSPs in the perforant path-dentate granule coll synapse. Exp Brain Res 12:46-63.

McNaughton BL, Morris RGM (1987) Hippocampal synaptic enhancement and information storage within a distributed memory system. Trends Neurosci 10:408-415.

McNaughton BL, Barnes CA, Meltzer J, Sutherland RJ (1989) Hippocampal granule cells are necessary for normal spatial learning but not for spatially-selective pyramidal cell discharge. Exp Brain Res 76:485-496.

Morris RGM, Garrud P, Rawlins JNP, O'Keefe J (1982) Place navigation impaired in rats with hippocampal lesions. Nature 297:681-683.

Morris RGM, Schenk F, Tweedie F, Jarrard LE (1990) Ibotenate lesions of hippocampus and/or subiculum: dissociating components of allocentric spatial lcarning. Eur J Neurosci 2:1016-1028.

Moser EI, Mathiesen I, Andersen P (1993a) Association between brain tcmperature and dentate field potentials in exploring and swimming rats. Science 259:1324-1326.

Moser EI, Moser M-B, Andersen P (1993b) Synaptic potentiation in the rat dentate gyrus during exploratory learning. NeuroReport 5:317-320.

Moser EI, Moscr M-B, Andersen P (1994) Potentiation of dentate syn apses initiated by exploratory learning: dissociation from brain temperature, motor activity and arousal. Lcarn Memory 1:55-73.

O'Keefe J, Dostrovsky J (1971) The hippocampus as a spatial map: preliminary evidence from unit activity in the freely-moving rat. Brain Res 34:171-175.
O'Keefe J, Nadel L (1978) The hippocampus as a cognitive map. Oxford: Clarendon.

Olton DS, Walker JA, Gage FH (1978) Hippocampal connections and spatial discrimination. Brain Res 139:295-308.

Rapp PR, Amaral DG (1988) The time of origin of somatostatinimmunoreactive neurons in the rat hippocampal formation. Dev Brain Res 41:231-239.

Scharfman HE (1991) Dentate hilar cells with dendrites in the molecular layer have lower thresholds for synaptic activation by perforant path than granule cells. J Neurosci 11:1660-1673.

Somogyi P, Hodgson AJ, Smith AD, Nunzi MG, Gorio A, Wu JY (1984) Different populations of GABAergic neurons in the visual cortex and hippocampus of cat contain somatostatin- or cholecystokininimmunoreactive matcrial. J Neurosci 4:2590-2603.

Staley KJ, Mody I (1992) Shunting of excitatory input to dentate gyrus granule cells by a depolarizing $\mathrm{GABA} \wedge$ receptor-mediated postsynaptic conductance. J Neurophysiol 68:197-212.

Steward O (1976) Topographic organization of the projections from the entorhinal area to the hippocampal formation of the rat. J Comp Neurol $167: 285-314$.

Steward O, White WF, Cotman CW, Lynch G (1976) Potentiation of excitatory synaptic transmission in the normal and in the reinnervated dentate gyrus of the rat. Exp Brain Res 26:423-441.

Struble RG, Desmond NL, Levy WB (1978) Anatomical evidence for interlamellar inhibition in the fascia dentata. Brain Res 152:580-585.

Sutherland RJ, Whishaw IQ, Kolb B (1983) A behavioural analysis of spatial localization following elcctrolytic, kainate or colchicine-induced damage to the hippocampal fonmation in the rat. Bulav Brain Res $7: 133-153$.

Thompson SM, Masukawa LM, Prince DA (1985) Temperature dependence of intrinsic membrane properties and synaptic potentials in hippocampal CA1 neurons in vitro. J Neurosci 5:817-824.

Treves A, Rolls ET (1992) Computational constraints suggest the necd for two distinct input systems to the hippocampal CA3 network. Hippocampus 2:189-199.

Vandcrwolf CH (1969) I Iippocampal clcctrical activity and voluntary movement in the rat. Electroencephalogr Clin Neurophysiol 26:407-418.

Walsh 'IJ, Schulz DW, 'T'ilson HA, Schmechel DE (1986) Colchicineinduced granule cell loss in rat hippocampus: selective behavioral and histological alterations. Brain Res 398:23-36.

Witter MP, Griffioen AW, Jorritsma-Byham B, Krijnen JIM (1988) Entorhinal projections to the hippocampal CA1 region in the rat: an underestimated pathway. Neurosci Lett 85:193 198.

Wu LG, Saggau P (1994) Presynaptic calcium is increased during normal synaptic transmission and paired-pulse facilitation, but not in long-term potentiation in area $\mathrm{CAl}$ of hippocampus. $J$ Neurosci 14:645-654.

Yeckel MF, Berger TW (1990) Feedforward excitation of the hippocampus by afferents from the entorhinal cortex: redefinition of the role of the trisynaptic pathway. Proc Nall Acad Sci USA $87: 5832-5836$.

Zalutsky RA, Nicoll RA (1990) Comparison of two forms of long-term potentiation in single hippocampal neurons. Scicnce 248:1619-1624. 